\title{
A cartografia como um mapa movente para a pesquisa em comunicação ${ }^{1,2}$
}

CARTOGRAPHY AS A MOVING MAP FOR COMMUNICATION RESEARCH

— Nísia Martins do Rosário

Professora e Pesquisadora do Programa de Pós-graduação em Comunicação da UFRGS

E-mail: nisiamartins@gmail.com

\section{Adriana Pierre Coca}

Doutora pelo Programa de Pós-graduação em Comunicação e Informação da Universidade Federal do Rio Grande do Sul

E-mail: pierrecoca@hotmail.com

Recebido em 28/07/2018. Aprovado em 21/09/2018.

\section{Resumo}

Nesta reflexão, colocamos em discussão os pressupostos basilares da perspectiva cartográfica (DELEUZE; GUATTARI, 1995), percorrendo as variações da atenção sugeridas por Kastrup (2007; 2008) e sinalizando o quanto essa metodologia de pesquisa pode nos auxiliar em processos de investigação, incluindo os estudos no campo da comunicação. Mais do que isso, ela prima pela construção de um percurso movente que se diferencia de pesquisador para pesquisador e, também, encaminha e torna particular cada abordagem.

Palavras-chave: Metodologia. Cartografia. Pesquisa em Comunicação.

\section{Abstract}

In this reflection, we put into discussion the basic assumptions of the cartographic perspective (DELEUZE; GUATTARI, 1995), traversing the variations of attention suggested by Kastrup (2007; 2008) and indicating how this research methodology can help us in the whole process of a research, including studies in the field of communication. More than this, we excel in the construction of a moving path that differentiates itself from researcher to researcher and we believe that it also directs us and makes each approach particular.

Keywords: Methodology. Cartography. Research in Communication.

1. Uma versão parcial desse artigo foi apresentada no XV Congresso Internacional Ibercom realizado de 16 a 18 de novembro de 2017, em Lisboa, Portugal.

2. Pesquisa financiada por: $\mathrm{CNPq}$ 


\section{Introdução: a perspectiva cartográfica}

No campo comunicacional, a cartografia é recente e ainda usada com parcimônia, por vezes se mesclada a outras metodologias. Acreditamos que o olhar cartográfico, por ser voltado para as multiplicidades e as diferenças, pode ser eficaz para pensar alguns objetos de investigação na comunicação a partir de determinadas epistemologias, como veremos ao longo deste texto. Ele está dividido em seis momentos: a presente introdução que resume os pressupostos basilares da cartografia; os tópicos seguintes que tratam da importância do rizoma para compreender esse método, do papel dos mapas moventes, dos modos de construir conhecimento, das variações da atenção propostas por Kastrup $(2007 ; 2008)$ que nos orientam nas fases de condução da pesquisa e as considerações finais.

A cartografia está associada ao pensamento pós-estruturalista e é uma perspectiva metodológica recente que pode ser compreendida como metodologia, método ou procedimento metodológico, dependendo do uso, da intenção de quem pesquisa e da dimensão que ela ocupa no processo. Partimos do princípio de que ela se configura como um método aplicável à comunicação tendo em vista a extensão da sua processualidade e a articulação que constrói com todas as etapas da pesquisa, inclusive com a teórica. Contudo, não pressupõe um método rígido, pelo contrário, irá sugerir " $[\mathrm{u}] \mathrm{m}$ trilhar metodológico que visa a construir um mapa (nunca acabado) do objeto de estudo, a partir do olhar atento e das percepções e observações do pesquisador, que são únicas e particulares, que serão cruzadas com a memória do investigador." (ROSÁRIO, 2008, p. 207).

Rosário (2016b) pensa a cartografia na comunicação como um caminho metodológico que traça um mapa inacabado do objeto de estudo a partir do olhar vigilante, aliado às percepções e observações do pesquisador-cartógrafo, que são únicas. Essa definição traz dois pressupostos fundantes da cartografia: a multiplicidade e a subjetividade. Tais pressupostos se contrapõem aos princípios da ciência moderna que coloca em evidência a objetividade, o raciocínio lógico e a fixidez de modelos metodológicos. Ainda que orientadas por esses preceitos, as pesquisas modernas não tiveram sucesso em eliminar a subjetividade que atravessa os processos que envolvem a investigação científica desde a percepção, interpretação até a teorização dos fatos e fenômenos. 


\section{viés do rizoma}

Deleuze e Guattari ${ }^{3}$ (1995) apontam a cartografia como um dos princípios do rizoma, que apresenta as seguintes características (que são nomeadas “princípios"): conexão, heterogeneidade, multiplicidade, ruptura a-significante e cartografia.

Entendemos que é importante trazer a noção de rizoma para que se possa imergir em aspectos que são integrantes da cartografia. O princípio da conexão sinaliza que o rizoma pode ser ligado em qualquer ponto. No rizoma não há uma hierarquia (com início, meio e fim), mas sempre um meio, ou seja, ele cresce em qualquer direção, por todos os lados. A pesquisa, a nosso ver, se constitui em linhas rizomáticas que vão, de acordo com o percurso de cada pesquisador, do teórico ao empírico e/ou de volta ao teórico e a outros percursos. Do mesmo modo, os resultados se configuram nesse 'caos'4 de linhas que vão se compondo na trajetória investigativa e que oferecem, assim, um mapa para a leitura dos vieses encontrados para a problemática.

O princípio da heterogeneidade, em reciprocidade com o anterior, indica que existem diferentes possibilidades de conexões. É justamente isso que faz cada pesquisa tão única e cada percurso tão afetado pelas pegadas do pesquisador que sintoniza tais conexões de acordo com a sua bagagem e o modo como organiza as entradas e saídas do rizoma-investigação. O princípio da multiplicidade, por sua vez, reforça a importância da diversidade de elementos que a construção rizomática proporciona: a multiplicidade rompe com o dualismo e a binariedade, propondo observar os elementos também por meio das suas singularidades e relações, que são os seus devires (DELEUZE; GUATTARI, 1995).

O deslocamento do rizoma acontece por meio de suas linhas, conexões e rupturas, e o quarto princípio da ruptura a-significante é aquele que assegura essa característica movente, afirmando que ele pode ser rompido em qualquer ponto, com maior ou menor intensidade. Rupturas que atravessam também as pesquisas, às vezes são esperadas, outras imprevisíveis, chamadas de linhas de fuga, podem operar na condução de novas criações.

O quinto princípio é o da cartografia e está diretamente vinculado ao rizoma, se desdobra nesse mapa construído a partir de múltiplas conexões e entradas (DELEUZE; GUATTARI, 1995). Fischer define a cartografia não como um método e/ou procedimento metodológico, "e sim como uma filosofia essencial para a reflexão metodológica e a arti-

3. Como se pode perceber pelo modo como classificam a cartografia, os autores não a entendiam como método ou metodologia, mas as apropriações de outros pesquisadores trouxeram à tona essa possibilidade atualizando temas e conceitos da ciência.

4. O caos é entendido aqui como um outra forma de organização que não segue os pressupostos cartesianos 
culação dos procedimentos para encaminhar cada problema de pesquisa" (2008, p. 222). Essa nos parece uma colocação assertiva para pensar esse princípio, pois acreditamos que ela evidencia a amplitude da cartografia que dá sustentação a todo o estudo, a partir do seu cerne, que são as questões-problema.

Desde a publicação de Mil Platôs I, a cartografia começou a ser aplicada como um método e/ou procedimento de pesquisa ${ }^{5}$ no Brasil, sobretudo nas áreas da Psicologia e da Educação. Nas pesquisas de comunicação ainda é pouco utilizada e se apresenta por vieses distintos, conforme observa Aguiar (2011). Nota-se que há trabalhos em que a cartografia se configura apenas como um mapeamento, um modo de levantar os dados ou realizar a pesquisa exploratória; outros pesquisadores assumem a cartografia só quando apresentam os resultados, como uma maneira de organizar as informações reunidas ao longo da investigação; há quem faça uso da cartografia como procedimento metodológico para análise do corpus; há aqueles que a aplicam para a coleta de dados de coletivos humanos e, finalmente, poucos a entendem como um modo de pensar e conduzir a pesquisa, aproximando-a de um método (ROSÁRIO, 2016a).

Importa considerarmos que, nessa última via, a cartografia pode ser um modo de pensar a comunicação, e talvez essa seja uma das suas maiores contribuições ao campo e também um obstáculo - instigante, sem dúvida - a quem se propõe a utilizá-la em sua investigação. É desafiador para o pesquisador cartografar, construir o seu próprio mapa/ rizoma - um mapa que está em constante movimento, já que a cartografia não oferece regras definidas por antecedência, um roteiro definido e fixo ou um método estabelecido de trabalho. Kastrup salienta que "cartografar é acompanhar um processo, e não representar um objeto" (2008, p. 469). Como destacam Deleuze e Guattari, esse mapa/rizoma se difere de qualquer decalque, e não oferece, portanto, uma forma estanque de trabalho: "O mapa é aberto, é conectável em todas as suas dimensões, reversível, suscetível de receber modificações constantemente" (1995, p. 22).

\section{Construção de mapas}

Rolnik acredita que a cartografia é um método que permite, a partir desse mapa, “detectar a paisagem, seus acidentes, suas mutações e, ao mesmo tempo, criar vias de passagem através deles" (1989, p. 6). Por isso, é fundamental compreender que esse mapa

5. É importante observar que Deleuze e Guattari não entendiam a cartografia como método, pelo contrário. Contudo, as apropriações feitas das reflexões desses autores levaram ao desenvolvimento das propostas que temos hoje. 
mutável é afetado por paisagens psicossociais e que o cartógrafo é um pesquisador com o corpo vibrátil, ou seja, que pode ser afetado pelas sensibilidades coletivas e pelos movimentos sociais (ROLNIK, 1989; 2006). Nesse sentido, a cartografia (sendo um mapa em constante atualização) pode revelar diferentes cenários sociais, trocas simbólicas ou mesmo fluxos comunicacionais, não podendo, assim, seguir protocolos normalizados previamente, uma vez que cada paisagem é única. "Como se propõe à criação/invenção, a cartografia encaminha-se sempre para a produção da diferença e para uma nova maneira de adquirir conhecimento" (ROSÁRIO, 2008, p. 210).

Tais colocações indicam que fazer uma cartografia é olhar para o objeto de estudo observando as suas repetições e, mais atentamente, as suas irregularidades. Quando falamos em "mapa movente", significa que o planejamento da pesquisa está sujeito a permanente alteração, tendo em conta que não se trata de um planejamento de modo cartesiano, pois são de fato indicativos que nos movem e que vão se constituindo ao longo da pesquisa. Assim, o mapa vai se formando na medida em que o campo (espaço e movimento) vai se constituindo aos olhos do cartógrafo, a partir de suas potenciais conexões engendradas pela heterogeneidade, pela multiplicidade e pelas rupturas a-significantes. Como metáfora, a ideia mais próxima de um mapa/rizoma que possamos ter talvez seja a imagem que conhecemos dos neurônios cerebrais, que se conectam uns aos outros em intermináveis encontros e estão sempre em atividade (movimento): esse é um dos exemplos dados por Deleuze e Guattari (1995) para nos auxiliar a decifrar esse conceito.

O termo cartografia na tradução do latim quer dizer carta escrita (charta, que significa carta; grafh, que significa escrever). O trabalho do registro das topologias do solo do cartógrafo/geógrafo é parecido com o processo cartográfico do cartógrafo/pesquisador: ambos passam pela observação detalhada do ambiente/território que querem investigar, exploram caminhos que se multiplicam em busca das especificidades, das diferenças, averiguam as formas que se repetem e as que destoam e, por fim, fazem a descrição cuidadosa do lugar, que vive em transformação.

O pesquisador-cartógrafo que desvenda esse terreno movediço e enredado deve estar ciente de que as suas interpretações são apenas um olhar que constrói um mapa/ rizoma repleto de irregularidades e conexões.

A cartografia compromete o sujeito com a busca da diferença, ou seja, com a procura de elementos, estratégias, argumentos, linhas de raciocínio que estão pulsando no objeto e que ainda não foram trazidos à tona; aceita as limitações da pesquisa e do pesquisador, sendo que esse consente a existência de outros pontos de vista além do seu (KASTRUP, 2008, p. 211). 
Rosário (2008; 2016b), no entanto, alerta que tal condição não significa que o envolvimento do cartógrafo com o objeto deixa de exigir uma observação cuidadosa e um discernimento do pesquisador, advertindo que - embora na perspectiva cartográfica a ciência não seja generalizante e construída sobre a rigidez - o rigor científico deve ser preservado. Um dos caminhos para escapar da rigidez, e ater-se ao rigor pode ser construído pelo deslocamento que se dá na transversalidade. Guattari (1981) a entende como um modo de ir além das horizontalidades (igualdade) e das verticalidades (hierarquias) estabelecendo uma dimensão do fora sem determinar fronteiras e lidando, portanto, com diferentes semióticas (significantes e não significantes). Por esse caminho, por um lado, os tensionamentos transparecem sem hierarquias e com a exposição das diferenças, por outro, as observações nunca estão dadas ou terminadas, o cartógrafo precisa deixar que as transformações do território o atravessem. "O plano da transversalidade [...] experimenta o cruzamento das várias forças que vão se produzindo a partir dos encontros entre os diferentes nós de uma rede de enunciação da qual emerge" (PASSOS; EIRADO, 2010, p. 115).

A cartografia pode ter muitos objetos empíricos, basta que a meta seja construir conhecimento a partir de um panorama (comunicacional no caso) dos movimentos e territórios encontrados em determinado fenômeno ou fato, numa perspectiva de criar com. O que indica o uso desse método é a postura do pesquisador frente a investigação desde o âmbito epistemológico como teoria que direciona a constituição do seu conhecimento.

Quando se trata de aproximar-se de sujeitos, algumas especificidades devem ser levadas em conta. Kastrup e Passos (2013), ao considerar a pesquisa de campo que lida com indivíduos para estudar a produção de subjetividade, verificam a dificuldade de construir conhecimento a partir de investigações que envolvem a relação entre pesquisador e pesquisado considerando territórios e semioses peculiares. No campo da comunicação a investigação que trabalha com pessoas tem problematizado os modos de contribuição, participação, autoria dos participantes. Levando em conta os âmbitos metodológicos que se apresentam no campo, são diversas as investigações que se voltam para a captura de conhecimento junto a pessoas ${ }^{6}$. Na maioria das vezes, os territórios e sujeitos não são conhecidos de antemão pelo pesquisador, o que demanda uma exploração sensível do ambiente. O que se busca na cartografia é construir um conhecimento com os participantes e não o conhecimento a partir deles. O plano de ação comum é a recomendação dos autores, que propõem: "acessar o plano do comum e também construir um mundo comum e, ao mesmo tempo, heterogêneo" (KASTRUP; PASSOS, 2013, p. 264).

6. É claro que a cartografia na comunicação, da forma como a entendemos, não precisa ser realizada só com pessoas (tradicionalmente chamadas de amostragem nas ciências duras), outros objetos do campo como os produtos midiáticos também podem ser objeto da cartografia 


\section{Conhecer com}

Reconhecemos que as condutas sugeridas pela cartografia não são usuais na comunicação, ainda que muitos aspectos epistemológicos, do método e das metodologias estejam sendo questionados, tensionados e repensados. Isso é resultado do tempo presente e não atinge só o nosso campo.

Conforme observamos, Kastrup e Passos (2013) entendem que a cartografia constitui um mundo comum ${ }^{7}$ e heterogêneo a partir da organização de um plano comum que se configura por linhas (rizomas) que conectam e atravessam as singularidades heterogêneas fazendo-as, inclusive, colidir. Isso implica, na maioria das vezes, primeiramente pensar sobre as posições teóricas e metodológicas assumidas pelo e nas suas práticas de pesquisa.

Uma das alterações de base trazidas pela cartografia é que a pesquisa deixa de ser apenas a produção de conhecimento do pesquisador sobre o campo para ser um construir com e, em decorrência, fazer valer o protagonismo do objeto permitindo a inclusão ativa deste no processo (PASSOS; BARROS, 2009). O que se apresenta nesse cenário é a desestabilização dos modos de organização do conhecimento.

Não é possível, por exemplo, considerar o sujeito com quem se vai fazer a pesquisa como um informante apenas, ele será o sujeito com quem se vai desenvolver a investigação, com quem se vai construir conhecimento. Neste ponto, é relevante considerar que a cartografia opera sobre o coletivo, extrapolando as disciplinas, as dimensões hierárquicas entre pesquisador e pesquisado,

[...] funcionando como zona de indiscernibilidade que não pertence exclusivamente a nenhum dos domínios específicos ou grupos de interesse implicados na pesquisa, mas diz respeito à complexidade da realidade investigada. A pesquisa cartográfica faz aparecer o coletivo, que remete ao plano ontológico, enquanto experiência do comum e, dessa maneira, é sempre uma pesquisa-intervenção com direção participativa e inclusiva, pois potencializa saberes até então excluídos, garante a legitimidade e a importância da perspectiva do objeto e seu poder de recalcitrância (KASTRUP; PASSOS, 2013, p. 266).

O trabalho pode ser atravessado pelos afetos de quem pesquisa, mas precisa apresentar uma condução reflexiva adequada, consistente. Se assim for, o cartógrafo trans-

7. Os autores consideram o entendimento de 'comum' por meio de François Jullien para quem o comum é um conceito político que está associado à transversalidade (a qual é também abordada nesse artigo) e se liga a ideia de heterogeneidade. "Não é dado a priori, mas se enraíza na experiência, se aprofundando e se enriquecendo com ela. Devemos construir um comum que não é pautado em relações de semelhança nem tampouco de identidade" (KASTRUP; PASSOS, 2013, p. 267).

Comunicação \& Inovação, PPGCOM/USCS

v.19, n. 41 [34-48] set-dez 2018 
muta no processo e, ao final da investigação, atinge um estado outro, caso em que a investigação terá realizado uma de suas funções, que é a de provocar um deslocamento no próprio cartógrafo-pesquisador. Isso porque terá havido, nessa conexão do sujeito com o objeto, um “compromisso ético e político com a ciência” (ROSÁRIO, 2016b, p.192).

Rolnik (2006) evidencia que a subjetividade do cartógrafo é afetada pelo mundo ao seu redor - que convoca a sua atenção, mas que também é povoado de elementos que a dispersam. Por sua vez, Kastrup (2008, p. 472) esclarece que as subjetividades se compõem por forças desiguais que se formam por vetores "sociais, políticos, tecnológicos, ecológicos, culturais, etc.”. Atravessada por esses vetores, a cartografia se constitui na direção contrária dos discursos hegemônicos, incentivando, portanto, a busca pela alteridade.

O que difere nessa construção é que os critérios podem ser mudados no caminho, exatamente porque o pesquisador é afetado por suas sensibilidades e pelo 'objeto'. Mas esses critérios existem e são indispensáveis para definir como será limitada a pesquisa. Nesse momento é relevante observar que o rigor se constitui na precisão, no detalhamento, na consistência, já a rigidez se volta para o engessamento, num formato único e intransigente. $\mathrm{O}$ conceito de método com regras rígidas, imutáveis e repetitivas, pautado pela racionalidade e pela objetividade é desconstruído pelo olhar cartográfico. Na tradição da ciência moderna o método se configura como o caminho a ser percorrido de acordo com regras determinadas previamente. A cartografia requer um outro posicionamento que ressignifica o próprio método: ele se faz na experimentação e na atitude de pesquisar.

Um roteiro também é um elemento necessário, sendo que, como já frisado várias vezes neste artigo, poderá ser recriado a qualquer instante. Outro elemento que Rolnik sugere ser levado em conta é o princípio: este apresenta os norteadores do estudo, as suas motivações.

A partir desse panorama, a análise do que foi colhido na investigação vai se voltar prioritariamente para o processo de pesquisa na relação com o problema concebido (o objeto emerge do problema). As fronteiras do objeto, nessa via, não são delimitados com rigor, tanto que Barros e Barros (2013, p. 375) afirmam que a análise "pode partir de um objeto com contornos precisos, mas alcança, progressivamente, um conjunto de múltiplas relações que lhe permite surgir como tal", sendo que aspectos inicialmente considerados externos acabam fazendo parte da investigação. A análise, em tal caso, não tem um procedimento específico (da ordem do 'como fazer'), um padrão fixo, tampouco definido por antecipação; para as autoras o procedimento deve ser definido pelo mergulho do cartógrafo na experiência da pesquisa tendo o problema de pesquisa como orientador. Diferen- 
temente do modo clássico de entender a análise na ciência, a cartografia reconhece que o pesquisador já está implicado na pesquisa e, deste modo, propõem "uma oposição radical às pretensões de neutralidade analítica do pesquisador [...)] $\mathrm{O}$ método analítico consiste, então, em dar visibilidade às relações que constituem uma dada realidade, na qual o pesquisador se encontra enredado" (BARROS; BARROS, 2013, P. 376).

Desprezando a separação sujeito/objeto e objetividade/subjetividade, essa perspectiva desconecta-se também da neutralidade em pesquisa, admitindo as implicações do pesquisador e das instituições no processo, bem como a incompatibilidade das generalizações e das homogeneidades. A análise envolve uma postura questionadora do cartógrafo em relação ao ambiente em que se insere, isso é fato, mas Barros e Barros (2013) sugerem indagar sobre os objetos, os sujeitos, os saberes, os processos de investigação, as totalidades, as relações constitutivas de territórios (como as práticas de saber-poder), as formas instituídas. É preciso enfrentar o deslocamento e experimentar a diferenciação.

\section{As variações da atenção: do rastreio ao toque}

Seguindo os princípios do rizoma, a cartografia tem muitas entradas, pode ser realizada considerando diversos percursos e direções que vão se organizando à medida que a pesquisa avança. O roteiro é apenas o início, as imprevisibilidades vão aparecendo e o caminho sendo reformulado. Kastrup (2007), no entanto, pode ajudar a compor um trajeto possível ao propor quatro variedades da atenção do cartógrafo, que inspiram na organização da pesquisa: o rastreio, o toque, o pouso e o reconhecimento atento.

A primeira fase, a do rastreio, é um "gesto de varredura do campo" (KASTRUP, 2007, p. 18). Não se trata, nesse processo, de uma busca de informação sistematizada, mas de abertura para conhecer o objeto e os afetos que possam surgir. É uma procura por conhecimento do objeto que se quer estudar pela atenção em suspensão e por meio de pistas que se configuram no campo, sem deixar que o conhecimento prévio do pesquisador afete essa busca. Ela pode se dar de dois modos: pelo viés da experiência empírica e também pela reflexão teórica.

É importante sublinhar que, quando sob suspensão, a atenção que se volta para o interior acessa dados subjetivos, como interesses prévios e saberes acumulados, ela deve descartá-los e entrar em sintonia com o problema que move a pesquisa. A atenção em si é, nesse sentido, concentração sem focalização, abertura, configurando uma atitude que prepara para o acolhimento do inesperado (KASTRUP, 2007, p.18). 
Na prática cartográfica: “A atenção não busca algo definido, mas torna-se aberta ao encontro" (KASTRUP, 2007, p.17). E, quando isso acontece, "[t]udo caminha até que a atenção, numa atitude de ativa receptividade, é tocada por algo" (KASTRUP, 2007, p. 19). É assim que se passa do rastreio ao toque: quando o toque é acionado, ingressamos na segunda fase da atenção, que é a seleção, algo que nos fisga porque salta no conjunto do que está sendo observado (KASTRUP, 2007). Não é busca pela informação ainda, é um reflexo, um vislumbre que acontece no nível das sensações, que pode ter graus diferentes de intensidades, ritmos e sentidos, e que não deve ser desprezado, porque é nesse processo que aprimoramos a seleção e que os critérios ficam mais claros.

Kastrup ressalta que "[a]través da atenção ao toque, a cartografia procura assegurar o rigor do método sem abrir mão da imprevisibilidade do processo de produção do conhecimento, que constitui uma exigência positiva do processo de investigação ad hoc" (2007, p. 19).

\section{Se movendo em zoom in: do pouso ao reconhecimento atento}

A etapa posterior toque é o pouso, quando é preciso perceber os pontos de intensidade, rupturas, repetições e desvios. Nas palavras de Kastrup, isso é possível quando realizamos, como em uma câmera de vídeo, um movimento de zoom: "há um trabalho fino e preciso, no sentido de um acréscimo na magnitude e na intensidade, o que ocorre para a redução do grau de ambiguidade da percepção" (2007, p. 20). É assim que o território de observação se reconfigura por meio de um foco, chamado pela autora de janelas atencionais que vão definir quadros de apreensão: "Cada janela cria um mundo e cada uma exclui momentaneamente as outras, embora outros mundos continuem copresentes" (KASTRUP, 2014, p. 44).

Os passos seguintes nos encaminham para a reflexão e compreensão dos variados pontos e linhas que constituem os platôs, assim como a organização dos mesmos. É a fase do reconhecimento atento, a última variedade atencional sugerida por Kastrup (2007). Esse é também um gesto de suspensão, entendemos que nessa etapa é necessário testar a correspondência entre o que se encontrou nas materialidades e os aspectos teóricos que estão em evidência na pesquisa. Essa fase da cartografia permite relacionar as linhas e conexões e ao longo do processo do reconhecimento atento inúmeros esboços de carto- 
grafias devem ser desenhados e refeitos, atualizações que vão se movendo a cada mirada para o objeto e a cada conexão teórica.

Kastrup explica que é nessa ativação da atenção que "[a] percepção se amplia, viaja percorrendo circuitos, flutua num campo plano, produzindo dados que, enfim, já estavam lá" (2007, p. 21), sendo que essa experiência é desencadeada porque "[d]e modo geral o fenômeno do reconhecimento é entendido como uma espécie de ponto de interseção entre a percepção e a memória" (2007, p. 20).

Esse viés da variação da atenção é demanda articulação com as relações teóricas, pois é o instante, segundo Kastrup (2007), em que os circuitos da cognição são acionados. Uma vez que as outras etapas de variação da atenção foram ativadas, essa condição permite a construção do seu próprio objeto de pesquisa através dos circuitos da atenção que foi percorrido. É por essa via que a pesquisa se torna uma genuína cartografia, visto que "o método cartográfico faz do conhecimento um trabalho de invenção, tal como indica a etimologia latina do termo invenire - compor com restos arqueológicos" (KASTRUP, 2007, p. 21).

Para um estudo chegar ao patamar do reconhecimento atento, com a criação dos platôs ganhando forma e movimento, significa que o caminho teórico também está sendo traçado e que no trajeto o cartógrafo-pesquisador direcionou o funcionamento da atenção à teoria e ao empírico. Num primeiro movimento, navegamos com concentração e sem focalização. A concentração existe, porque está em uma sintonia fina com o problema de pesquisa. Esse ponto de partida se dá quando a atenção do cartógrafo está disposta como um gesto que tateia, que explora ao redor, sem dar respostas ou esboçar nenhum tipo de ação imediata. "De todo modo, é preciso ressaltar que em cada momento na dinâmica atencional é todo o território da observação que se reconfigura" (KASTRUP, 2007, p. 20). O passo derradeiro, o reconhecimento atento, como já colocado, reconfigura novamente a percepção do cartógrafo-pesquisador e aciona a memória por meio de circuitos.

\section{Considerações finais}

A cartografia como um pensamento de Deleuze e Guattari (1995) foi apropriada por outros pesquisadores e desenvolvida como possibilidade de método e/ou de procedimento metodológico. Os autores sugerem que o mapa construído se revele a partir de rizomas, com pontos de intensidades, linhas distintivas e conexões diversas que se movem e vão traçando um cenário - nunca acabado. Nesse sentido, o percurso de cada pesquisador-cartógrafo é diferente porque está conectado às suas experiências, às suas 
subjetividades, ou seja, cada estudo tem o seu mapa/rizoma tecido com coordenadas que diferem entre si. Entende-se que o múltiplo, o rizoma, as conexões e a diferença são elementos que habitam as investigações realizadas na área de ciências sociais e humanas de caráter qualitativo. $\mathrm{O}$ que determinados pesquisadores fazem não considerar esses elementos moventes e reorganizar o conhecimento encaminhando para uma via cartesiana e positivista de acordo com o que prega a ciência moderna. Na postura que ultrapassa esse modo de pesquisar, a cartografia é pertinente à comunicação.

A multiplicidade está intimamente vinculada ao rizoma e é uma de suas características, permitindo observar as singularidades do objeto de pesquisa (como elementos que constituem o múltiplo), que são pontos fundamentais de toda cartografia, ou seja, as diferenças desse objeto. Já na subjetividade está imbuída a ideia de processualidade, e quando falamos em configurações de subjetividades na formação dos mapas/rizomas alertamos para o caráter potencialmente oscilante de mudanças no processo, porque os rizomas formadores das cartografias são compostos por vetores heterogêneos: políticos, sociais, econômicos, ecológicos, tecnológicos e também os comunicacionais.

Um aspecto importante da cartografia que entendemos que se deve reter é o seu entendimento de método de investigação como criador da realidade, o que tensiona o paradigma da representação. Nas palavras de Kastrup e Passos (2013) não se trata de descobrir o que é dado como natureza ou realidade preexistente, mas intervir na realidade e nesse processo fazer emergir a criação. Buscar o conhecimento desse modo, implica, portanto, em transformar a realidade, obter um mundo que está nas mãos do pesquisador e isso envolve um comprometimento ético, político com o ato do conhecimento - conforme já afirmamos.

Torna-se também relevante o modo de conexão do pesquisador com a pesquisa. Nessa via, Kastrup e Passos (2013, p.266) afirmam que:

A dimensão interativa ou participativa característica da experiência de "inter-esse" é revalorizada, o que confere ao trabalho da pesquisa um sentido de cuidado. O pesquisador sai da posição de quem - em um ponto de vista de terceira pessoa - julga a realidade do fenômeno estudado, para aquela posição - ou atitude (o ethos da pesquisa) - de quem se interessa e cuida.

Por essa via, compreendemos que a cartografia está condicionada a um trabalho movente e, por conseguinte, ligada a acompanhamento de processos; tende a proliferar 
sentidos ao invés de resultados únicos. Se modifica a cada descoberta, despertar do objeto ou impacto externo, sem seguir à risca um método previamente determinado, nessa linha é preciso considerar que o método vai se construindo no percurso da pesquisa. Dessa maneira, o pesquisador é incitado a criar o próprio movimento - não sem o rigor científico necessário, com critérios que devem orientá-lo, e tendo um planejamento, um plano comum ou um roteiro orientador.

Esse processo de pesquisa é, sem dúvida, novo na comunicação, seus usos são ainda bastante incipientes, o próprio entendimento do que é cartografia diverge entre os pesquisadores que se apropriam desse termo. Pode-se dizer que a comunicação ainda vive uma fase experimental da cartografia que deverá ir se constituindo à medida em que seus usos forem multiplicados e aceitos - ou não. Esse método, contudo, não deve nunca se dar por atualizado definitivamente, está sempre em movimento e, por isso, as contribuições que pode trazer ao campo da comunicação são importantes, uma vez que propõe constante reflexão sobre si mesmo e está em conexão com uma visão de ciência inserida no contemporâneo. Renova os modos de pensar e entender a pesquisa e também requalifica as maneiras de aproximar-se do objeto.

A cartografia na comunicação vai provocar diversas ordens de desterritorialização do pesquisador, primeiro em relação ao seu entendimento de ciência e de método, mas tem conexão também com a postura para iniciar o processo de investigação, a forma de coletar informações e interpretar os dados. Os procedimentos metodológicos mais usados na comunicação partem de um modelo (pronto) e a cartografia vai propor que se tenha, de saída, apenas um roteiro, à medida que a pesquisa se coloca em movimento encontra tensionamentos sobre os quais é necessário refletir e fazer escolhas sobre novos percursos, outras organizações e sistematizações.

Essa desterritorialização, inclusive, precisa se dar sobre o que se chama costumeiramente de conhecimento. Este se constrói pela análise de processos, pelo entendimento de que não há uma efetiva separação entre sujeito e objeto, entre subjetividade e objetividade. Alvarez e Passos (2010, p.138) lembram que entender o território pesquisado na relação dualista (do concreto ao abstrato, do geral ao particular) apenas gera um ponto de vista desencarnado, um discurso desarticulado. Constitui-se aí a diferença entre o saber sobre e o saber com. Esse último aprende com os fenômenos, pois dispõe-se a acompanhá-los e a reconhecer suas singularidades. Assim, o saber com é, para nós, o princípio da cartografia e deveria ser o da ciência contemporânea. 


\section{Referências}

AGUIAR, L. M. Processualidades da Cartografia nos usos teórico metodológicos de pesquisas em comunicação social. São Leopoldo, RS. Dissertação de Mestrado. Universidade do Vale do Rio dos Sinos, 2011. 150 p.

ALVAREZ, J.; PASSOS, E. Cartografar é habitar um território existencial. In: PASSOS, E.; KASTRUP, V.; ESCÓSSIA, L. (orgs.). Pistas do método da cartografia: Pesquisa-intervenção e produção de subjetividade. Porto Alegre: Sulina, 2015.

BARROS, L.M.R; BARROS, M. E. B. O problema da análise em pesquisa cartográfica. Fractal Revista de Psicologia. v.25 - n.2, p.373 - 390, maio/ago. 2013.

DELEUZE, G.; GUATTARI, F. Mil Platôs: capitalismo e esquizofrênia. Volume 01. Rio de Janeiro: Editora 34, 1995.

GUATTARI, F. Transversalidade. In: ROLNIK, S. (Org.). Revolução molecular: pulsações políticas do desejo. São Paulo: Brasiliense, 1981.

KASTRUP, V. (2007). O funcionamento da atenção no trabalho do cartógrafo. Revista Psicologia \& Sociedade. Rio de Janeiro, p. 15-22. Disponível em: <http://www.scielo.br/scielo.php?scrip$\mathrm{t}=$ sci_arttext\&pid=S0102-71822007000100003>. Acesso em: 22 set. 2017.

. O método da cartografia e os quatro níveis da pesquisa-intervenção. In: L. R. CASTRO; V. L. BESSET (orgs.). Pesquisa-intervenção na infância e juventude. 1 ed. Rio de Janeiro: Nau, v.1, p. 465-489, 2008.

ROLNIK, S. Cartografia sentimental: transformações contemporâneas do desejo. São Paulo: Estação Liberdade, 1989.

Cartografia sentimental: transformações contemporâneas do desejo. Porto Alegre: Editora da Universidade Federal do Rio Grande do Sul, 2006.

PASSOS, E.; KASTRUP, V.; ESCÓSSIA, L. (orgs.). Pistas do método da cartografia: Pesquisa-intervenção e produção de subjetividade. Porto Alegre: Sulina, 2015.

ROSÁRIO, N. M. Mitos e cartografias: novos olhares metodológicos na comunicação. In: A. E. MALDONADO; J. A. BONIN; N. M. ROSÁRIO (orgs.). Perspectivas metodológicas em comunicação: desafios na prática investigativa. João Pessoa: Editora Universitária da UFPB, 2008. 
. Cartografia na comunicação: questões de método e desafios metodológicos. Palestra realizada na FABICO/UFRGS no I Colóquio Internacional de Investigação Crítica em Comunicação, em 26 de julho, 2016a.

. Cartografia na comunicação: questões de método e desafios metodológicos. In: M. I. V. LOPES; C. P. MOURA (orgs.). Pesquisa em comunicação: metodologias e práticas acadêmicas. Porto Alegre: EDIPUCRS, 2016b. 